Academic Platform Journal of Engineering and Science

journal homepage: https://dergipark.org.tr/tr/pub/apjes

\title{
Expert Modelling and Prediction of Von Mises Stresses in High Speed Steel Cutting Tool Using FEM (ANSYS)
}

\author{
${ }^{1}$ Cyril Aliyegbenoma, ${ }^{2}$ Mercy Ozakpolor \\ ${ }^{1}$ Department of Production Engineering, Faculty of Engineering, University Of Benin, Benin City, Edo State, Nigeria \\ *1 cyril.aliyegbenoma@eng.uniben.edu, \\ 2othuke2477@gmail.com,
}

Research Paper

Arrival Date: 22.05 .2020

Accepted Date: 14.01 .2021

\begin{abstract}
In the machining world, development of predictive models is one remedy to reducing tool failure and its associated challenges like reduction in integrity of machined parts, production shutdown and idle time for machine operators.

In this research, we want to show how robust the Finite Element (ANSYS) method is, by comparing its predictive capacity to the experimental machining operation.

To achieve the scope of the study, Seventeen (17) varying set of experiments were conducted for the cutting tool using the three levels Box-Behnken's design (BBD) of experiment at varying process parameters of 200-600 rpm spindle speed, $0.05-0.15 \mathrm{~mm} / \mathrm{rev}$ feed rate and $0.5-1.5 \mathrm{~mm}$ depth of cut. During, the orthogonal cutting of AISI 1010 mild steel measuring $200 \mathrm{~mm}$ length by $44 \mathrm{~mm}$ diameter, the electrical strain gauge connected to the Electronic strain meter E10 was used to measure the tools' induced strains from where the equivalent von mises stresses were generated for the research. The finite element software was then used to model the HSS tool for prediction of the concerned response based on the designed matrix generated by the Design Expert. The experimental values were compared with the ANSYS simulated values using the absolute mean percentage error and the reliability plot.
\end{abstract}

At the end, both the experimental and FEM (ANSYS) readings were in close agreements with a mean absolute percentage error of $0.544 \%$. Therefore, this research has clearly shown that ANSYS is a very robust expert tool that can be used to model and predict von mises stresses in HSS cutting tool.

Keywords: BBD, FEM, HSS, ANSYS, Cutting tool, ENC, Von-mises stress.

\section{INTRODUCTION}

The metal cutting process is a deformation process that uses a cutting tool to remove unwanted material from a work piece produce designed specifications. It is the oldest and most vital form of machining in the manufacturing world. Technically, it has advanced from the traditional and manual cutting method to the newest manufacturing technique that has many processes with automated tools design for high quantities and precisions. These modern heavy machine tools like the computer numerically controlled (CNC) lathes have be found to generate more heat than the simple manual tools due to the sliding friction of the chip on the rake face. The heat produced during the operation brings about abnormal thermal gradient in the form of von mises stresses due to high strains. The produced von mises stress is the major cause of tool fracture, fatigue and failure at last. A situation resulting from loses of bindings within the crystals in the tool materials [1]. Besides, literature has shown that the major cause of increasing cutting temperature and von mises stress is uncontrolled process parameters, since cutting tools have specific geometry. Experimental investigations carried out on the process parameter of a cutting tool and its influence on cutting forces and surface roughness for finished Hard Turning operation using MDN250 steel, the experimental operation involved cutting speed, depth of cut and feed rate as control variables, while feed force, surface roughness and the thrust force were taken as response parameters [2]. During the experiment, the flank wear was measured with tool maker's microscope. And at the end, the work prove that good surface appearance in material can be attained when cutting speed, depth of cut are set close to their high level $(93 \mathrm{~m} / \mathrm{min}$ and $0.2 \mathrm{~mm}$ respectively) 
with feed rate at low level of $0.04 \mathrm{~mm} / \mathrm{rev}$. A methodology for the determination of work piece flow stress and the friction at the chip-tool interface during the high-speed cutting at high deformation rates due to the high cutting temperatures of the cutting zone. Their results were used to stimulate the highspeed machining using the finite element analysis based program. The flow stress model based on process dependent parameters like the stain, strain-rate and temperature were used together with the friction model so as to enable them to determine the unknown parameters of the flow stress and the friction model [3]. Most commonly used method for the determination of flow stresses are the tension, uniform and torsion tests was postulated [4].

They analyzed the role of flow stresses and friction coefficient on machining using finite element analysis. In their work, the coulomb friction model was cited as the commonly used technique in most finite element method while the Jonson-cook constitutive law was presented as a prerequisite predictive model [5].

They also analyzed the residual stresses induced by dry turning on difficult- to- machined materials. Their focus was on the effects of cutting process parameters on the residual stresses and surface integrity while turning Inconel 718 and Austentic stainless steel AISI 318L under dry condition with coated and uncoated carbide tools. A three- dimensional predictive finite element model was developed and on comparing both the predicted and experimental result, a new knowledge on surface integrity in terms of residual stresses was developed [6].

The quantitative analysis of the flow stress constitutes one of the most important inputs to the simulation of a metal forming process. The authors also stated that the flow stress of a metal may be quantified in terms of its dependence on strain, strainrate and temperature. They further stressed that the flow stress can also be based on the internal state variables such as dislocation, density, grain size, phase formation, as well strainrate and temperature [7].

The investigation on the influence of tool wear on surface roughness using differently shaped ceramic tools in a hard turning operation was carried out [8]. The surface roughness was determined by the macroscopic tool geometry at certain levels of feed rates. Others that also studied on similar research issue [9][10].

\section{MATERIALS AND METHODS}

\subsection{Experimental Method}

The experimental cutting test in this work, involved the dry cutting of a cylindrical mild steel bar of $200 \mathrm{~mm}$ length by $44 \mathrm{~mm}$ diameter using the industrial 2060 ENC model Lathe machine. The high speed steel single point cutting tool was employed for the machining operation. The Box-Behnken Design (BBD) of experiment was adopted for this work, table 1 shows the cutting parameters which are the spindle speed, depth of cut and feed rate. From table 1, seventeen (17) experimental test were generated for the research. While, Table 2 shows the generated BBD matrix for the three process parameters as well as the response obtained after the experiment.

Table 1: Cutting parameters and their corresponding levels

\begin{tabular}{|l|l|l|l|l|}
\hline Tools Types & & \multicolumn{3}{l|}{ High speed steel (HSS) } \\
\hline $\begin{array}{l}\text { Work piece } \\
\text { materials }\end{array}$ & \multicolumn{4}{|l|}{ Mild Steel } \\
\hline $\begin{array}{l}\text { Cutting } \\
\text { parameters }\end{array}$ & $\begin{array}{l}\text { Symbols/ } \\
\text { units }\end{array}$ & $\begin{array}{l}\text { Low } \\
(-1)\end{array}$ & $\begin{array}{l}\text { Medium } \\
(0)\end{array}$ & $\begin{array}{l}\text { High } \\
(+1)\end{array}$ \\
\hline Spindle speed & n, rpm & 200 & 400 & 600 \\
\hline Feed rate & f,mm/rev & 0.05 & 0.1 & 0.15 \\
\hline Depthof cut & ap, mm & 0.5 & 1.0 & 1.5 \\
\hline
\end{tabular}

Table 2: Experimental data for high speed steel cutting tool while machining mild steel

\begin{tabular}{|l|l|l|l|l|}
\hline $\begin{array}{c}\text { Test } \\
\text { No }\end{array}$ & $\begin{array}{c}\text { Spindle } \\
\text { speed, } \mathrm{n} \\
(\mathrm{rpm})\end{array}$ & $\begin{array}{c}\text { Feed } \\
\text { rate }, \mathrm{f} \\
(\mathrm{mm} / \\
\mathrm{rev})\end{array}$ & $\begin{array}{c}\text { Depth } \\
\text { of cut, } \\
\text { ap } \\
(\mathrm{mm})\end{array}$ & $\begin{array}{c}\text { Von } \\
\text { mises } \\
\text { stresses } \\
\mathrm{N} / \mathrm{mm}^{2}\end{array}$ \\
\hline 1 & 200 & 0.15 & 1.00 & 275.50 \\
\hline 2 & 400 & 0.05 & 1.50 & 755.80 \\
\hline 3 & 600 & 0.10 & 1.50 & 1353.0 \\
\hline 4 & 200 & 0.10 & 0.50 & 461.50 \\
\hline 5 & 600 & 0.05 & 1.00 & 510.50 \\
\hline 6 & 400 & 0.05 & 0.50 & 260.10 \\
\hline 7 & 600 & 0.10 & 0.50 & 462.50 \\
\hline 8 & 600 & 0.15 & 1.00 & 1290.1 \\
\hline 9 & 400 & 0.10 & 1.00 & 907.45 \\
\hline 10 & 200 & 0.05 & 1.00 & 518.56 \\
\hline 11 & 400 & 0.15 & 1.50 & 1915.9 \\
\hline 12 & 400 & 0.10 & 1.00 & 907.51 \\
\hline 13 & 400 & 0.10 & 1.00 & 907.50 \\
\hline 14 & 400 & 0.10 & 1.00 & 907.50 \\
\hline 15 & 400 & 0.10 & 1.00 & 907.51 \\
\hline 16 & 400 & 0.15 & 0.50 & 650.00 \\
\hline 17 & 200 & 0.10 & 1.50 & 1363.9 \\
\hline
\end{tabular}

Figure 1 shows the experimental set-up, where a strain meter connected to a single electrical strain guage was used to take readings from which the induced equivalent stresses were generated. 


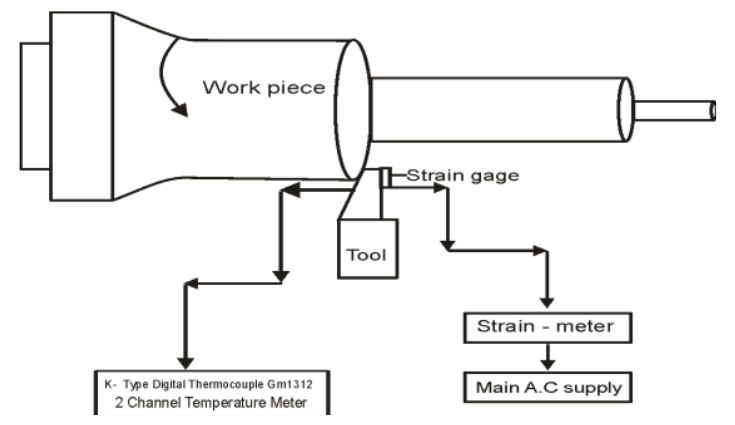

Figure 1: Experimental set-up

\subsubsection{FEM Simulation}

Finite element software such as ANSYS is a tool used for simulating the behavior of cutting tool during machining. It analyzes finite element problem in three steps, namely: preprocessing, solution and post processing [11] as explained below.

\subsubsection{Preprocessing:}

This includes defining the geometrical properties of the problem, the element types to be used, the material properties of the elements, the geometrical properties of the elements loadings. Thirdly, is to analysis the setting where the boundary conditions such as fixed support, applied force, pressure etc. are specified. However, to find the induced stresses on the cutting tool, the cutting force should be known.

In this study, AutoCAD Inventor was used for the model design.

(length, area etc.), the element connectivity (mesh the model), the physical constraints (boundary conditions) and the

After the geometry modeling, we exported the geometry to ANSYS for nodes and elements generation for the meshed cutting tool. The fixed support for the cutting tool was movement restricted in the top and bottom part. The various applied forces are determined from the spindle speed, feed rate and depth of cut values using equation (1) as given in table 3. The force is the force reaction coming from the work piece which is equal and opposite to the actual cutting force applied. These values were inputted to ANSYS.

For turning operation using high speed steel tipped tool with $\alpha=+10^{\circ}, \lambda=45^{\circ}, \mathrm{R}=2 \mathrm{~mm}, \mathrm{i}=0^{\circ}, \mathrm{C}=10^{\circ}, \quad$ without lubrication, the relation is:

$$
\mathrm{F}_{\mathrm{c}}=\mathrm{Cd}^{\mathrm{x}} \mathrm{f}^{\mathrm{y}} \mathrm{V}^{\mathrm{n}}, \mathrm{kgf}
$$

Where

$\mathrm{F}_{\mathrm{c}}=$ cutting force, $\mathrm{N}$

$\mathrm{f}=$ feed, $\mathrm{mm} / \mathrm{rev}$ $\mathrm{d}=$ depth of cut, $\mathrm{mm}$ $\mathrm{V}=$ cutting speed, $\mathrm{m} / \mathrm{min}$

For work material such as steel and steel castings, with tensile strength of $75 \mathrm{kgf} / \mathrm{mm}^{2}$ and feed less than or equal to $0.75 \mathrm{~mm} / \mathrm{rev}$ take $\mathrm{C}=300, \mathrm{x}=1.0, \mathrm{y}=0.75, \mathrm{n}=-0.15$ [12].

Table 3: Summary of cutting tool force

\begin{tabular}{|l|l|l|l|l|}
\hline $\begin{array}{l}\text { Test } \\
\text { No }\end{array}$ & $\begin{array}{l}\text { Spindle } \\
\text { Speed } \\
\text { (rpm) }\end{array}$ & $\begin{array}{l}\text { Feed rate } \\
(\mathrm{mm} / \\
\text { rev })\end{array}$ & $\begin{array}{l}\text { Depth } \\
\text { of cut }(\mathrm{mm})\end{array}$ & Forces (N) \\
\hline 1 & 200 & 0.15 & 1.00 & 43.94772225 \\
\hline 2 & 400 & 0.05 & 1.50 & 26.06346724 \\
\hline 3 & 600 & 0.10 & 1.50 & 41.24686998 \\
\hline 4 & 400 & 0.10 & 0.50 & 16.21204987 \\
\hline 5 & 600 & 0.05 & 1.00 & 16.35035708 \\
\hline 6 & 400 & 0.05 & 0.50 & 8.687822414 \\
\hline 7 & 600 & 0.10 & 0.50 & 13.74895666 \\
\hline 8 & 600 & 0.15 & 1.00 & 37.27075435 \\
\hline 9 & 400 & 0.10 & 1.00 & 29.2222349 \\
\hline 10 & 200 & 0.05 & 1.00 & 19.27948506 \\
\hline 11 & 400 & 0.15 & 1.50 & 59.41185751 \\
\hline 12 & 400 & 0.10 & 1.00 & 29.2222349 \\
\hline 13 & 400 & 0.10 & 1.00 & 29.2222349 \\
\hline 14 & 400 & 0.10 & 1.00 & 29.2222349 \\
\hline 15 & 400 & 0.10 & 1.00 & 29.2222349 \\
\hline 16 & 400 & 0.15 & 0.50 & 19.8039525 \\
\hline 17 & 200 & 0.10 & 1.50 & 48.63614962 \\
\hline 17 & 200 & 0.10 & 1.50 & 48.63614962 \\
\hline
\end{tabular}

Solution: The features in this step such as matrix manipulation, numerical integration, and equation solving are carried out automatically by the software. The governing algebraic equation in matrix form, computation of the unknown values of the primary field and assembling is done automatically.

\section{FINDINGS}

In this section is the evaluation and interpretation of the various von mises stresses will be presented.

\subsection{RESULTS}

Post processing: Interpretation and evaluation of results is expressed this stage.

For a turning operation with spindle speed of $200 \mathrm{rpm}$, feed rate of $0.15 \mathrm{~mm} / \mathrm{rev}$ and a depth of cut of $1 \mathrm{~mm}$, the stress of $1278.20 \mathrm{~N} / \mathrm{mm}^{2}$ was generated on the cutting tool. Figure 2 shows the stress buildup from minimum to maximum during the turning process, when a cutting force of $43.9477 \mathrm{~N}$ was applied. 


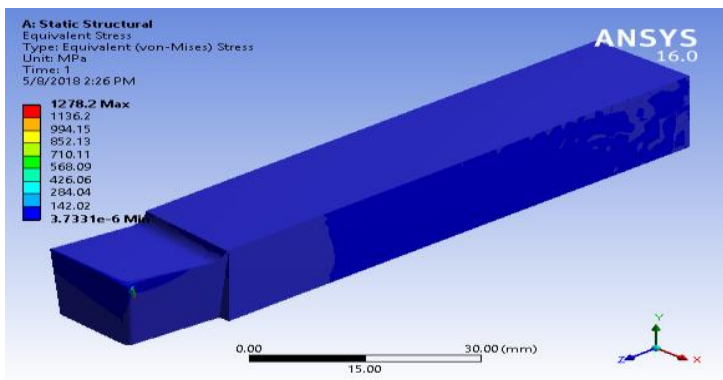

Figure 2: von-mises stress for cutting force Of $43.9477 \mathrm{~N}$ using FEM

For a turning operation with spindle speed of $400 \mathrm{rpm}$, feed rate of $0.05 \mathrm{~mm} / \mathrm{rev}$ and a depth of cut of $1.50 \mathrm{~mm}$, the stress of $764.44 \mathrm{~N} / \mathrm{mm}^{2}$ was generated on the cutting tool. Figure 3 shows the stress buildup from minimum to maximum during the turning process, when a cutting force of $26.0635 \mathrm{~N}$ was applied.

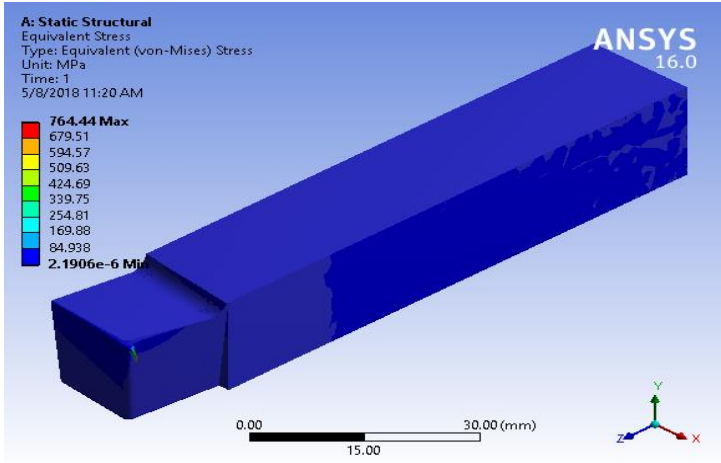

Figure 3 von-mises stress for cutting force Of 26.0635N using FEM

For a turning operation with spindle speed of $600 \mathrm{rpm}$, feed rate of $0.10 \mathrm{~mm} / \mathrm{rev}$ and a depth of cut of $1.50 \mathrm{~mm}$, the stress of $1365.90 \mathrm{~N} / \mathrm{mm}^{2}$ was generated on the cutting tool. Fig. 4 shows the stress buildup from minimum to maximum during the turning process, when a cutting force of $41.2469 \mathrm{~N}$ was applied

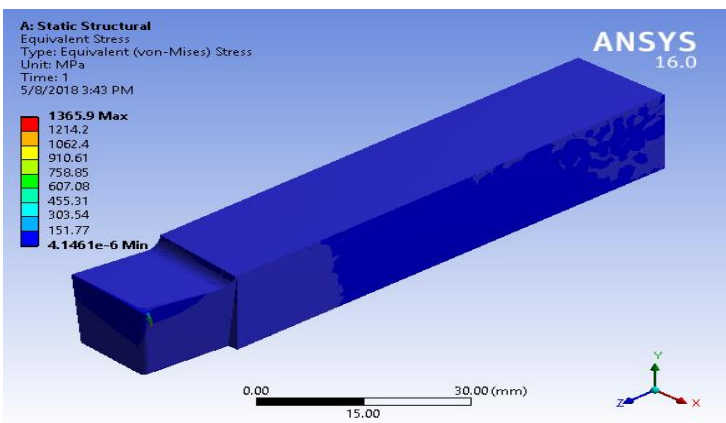

Figure 4 von-mises stress for cutting force of 41.2469N using FEM
For a turning operation with spindle speed of $400 \mathrm{rpm}$, feed rate of $0.10 \mathrm{~mm} / \mathrm{rev}$ and a depth of cut of $0.50 \mathrm{~mm}$, the stress of $464.25 \mathrm{~N} / \mathrm{mm}^{2}$ was generated on the cutting tool. Figure 5 shows the stress buildup from minimum to maximum during the turning process, when a cutting force of $16.2120 \mathrm{~N}$ was applied

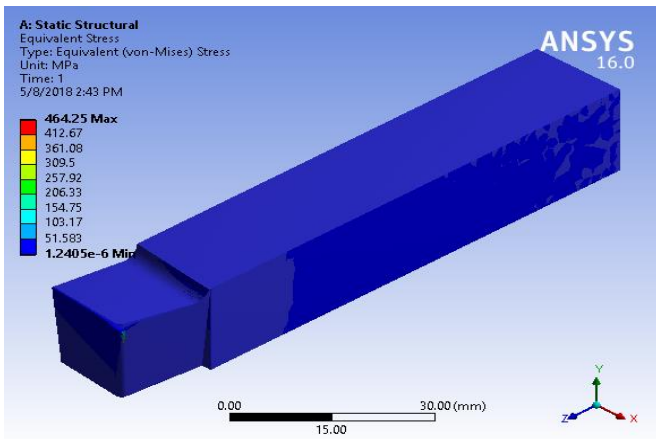

Figure 5 von-mises stress for cutting force of $16.2120 \mathrm{~N}$ using FEM

The same predictive approach was used for experiment numbers 5-17. See the summary of the maximum ANSYS predicted response values obtained for the BBD design of experiment in Table 4 below

Table 4: Summary of ANSYS generated Von-mises Stresses for HSS cutting tool

\begin{tabular}{|l|l|l|l|l|}
\hline $\begin{array}{l}\text { Test } \\
\text { No }\end{array}$ & $\begin{array}{l}\text { Spindle } \\
\text { Speed } \\
(\mathrm{rpm})\end{array}$ & $\begin{array}{l}\text { Feed } \\
\text { rate } \\
(\mathrm{mm} / \mathrm{rev})\end{array}$ & $\begin{array}{l}\text { Depth } \\
\text { of cut } \\
(\mathrm{mm})\end{array}$ & $\begin{array}{l}\text { Von mises } \\
\text { Stress } \\
\left(\mathrm{N} / \mathrm{mm}^{2}\right)\end{array}$ \\
\hline 1 & 200 & 0.15 & 1.00 & 1278.20 \\
\hline 2 & 400 & 0.05 & 1.50 & 764.44 \\
\hline 3 & 600 & 0.10 & 1.50 & 1365.90 \\
\hline 4 & 400 & 0.10 & 0.50 & 464.25 \\
\hline 5 & 600 & 0.05 & 1.00 & 511.10 \\
\hline 6 & 400 & 0.05 & 0.50 & 262.63 \\
\hline 7 & 600 & 0.10 & 0.50 & 464.25 \\
\hline 8 & 600 & 0.15 & 1.00 & 1278.20 \\
\hline 9 & 400 & 0.10 & 1.00 & 910.56 \\
\hline 10 & 200 & 0.05 & 1.00 & 511.10 \\
\hline 11 & 400 & 0.15 & 1.50 & 1920.00 \\
\hline 12 & 400 & 0.10 & 1.00 & 910.56 \\
\hline 13 & 400 & 0.10 & 1.00 & 910.56 \\
\hline 14 & 400 & 0.10 & 1.00 & 910.56 \\
\hline 15 & 400 & 0.10 & 1.00 & 910.56 \\
\hline 16 & 400 & 0.15 & 0.50 & 649.24 \\
\hline 17 & 200 & 0.10 & 1.50 & 1365.90 \\
\hline & & & &
\end{tabular}

\section{DISCUSSION}

The prediction of high speed steel cutting tool von mises stresses when machining mild steel using dry orthogonal cutting process was carried out, using both experimental methods and the finite element method. This is to know how 
accurate the FEM could predict the stresses generated on the tool. The Box-Behnken's experimental design with the aid of the Design Expert 7.00 version was used to generate the design of experiment (DOE) as shown in table 6. The vonmises stresses obtained in table 2 is the experimental values. To get the FEM stress values, the forces gotten from table 3 using equation (1), were employed to generate the von-mises stresses in table 4 . At the end, a comparative study between the experimental and FEM using the absolute mean percentage error was given in table 5 .

Table 5: FEM comperitave prediction of von-mises stresses and experimental reading

\begin{tabular}{|c|c|c|c|}
\hline Test No & $\begin{array}{c}\text { Von mises } \\
\text { stress } \\
\text { N/mm } \\
\text { Experimen } \\
\text { tal }\end{array}$ & $\begin{array}{c}\text { Von mises } \\
\text { stress } \\
\text { N/mm } \\
\text { FEM } \\
\text { predicted }\end{array}$ & $\begin{array}{c}\text { Absolute } \\
\text { percentag } \\
\text { e error } \\
(\%)\end{array}$ \\
\hline 1 & 1275.50 & 1278.20 & 0.21 \\
\hline 2 & 755.80 & 764.44 & 1.14 \\
\hline 3 & 1353.00 & 1365.90 & 0.95 \\
\hline 4 & 461.50 & 464.25 & 0.96 \\
\hline 5 & 510.50 & 511.10 & 0.12 \\
\hline 6 & 260.10 & 262.63 & 0.97 \\
\hline 7 & 462.50 & 464.25 & 0.38 \\
\hline 8 & 1290.10 & 1278.20 & 0.92 \\
\hline 9 & 907.45 & 910.56 & 0.34 \\
\hline 10 & 518.56 & 511.10 & 1.44 \\
\hline 11 & 1915.95 & 1920.00 & 0.21 \\
\hline 12 & 907.51 & 910.56 & 0.33 \\
\hline 13 & 907.50 & 910.56 & 0.34 \\
\hline 14 & 907.50 & 910.56 & 0.34 \\
\hline 15 & 907.51 & 910.56 & 0.33 \\
\hline 16 & 650.00 & 649.24 & 0.12 \\
\hline 17 & 1363.90 & 1365.90 & 0.15 \\
\hline
\end{tabular}

The Mean Absolute Error is 0.544\%

To assess the accuracy of the predictions as well as the suitability of the Expert model, a reliability plot of the experimental and the finite element was carried out, as shown in Figure 6

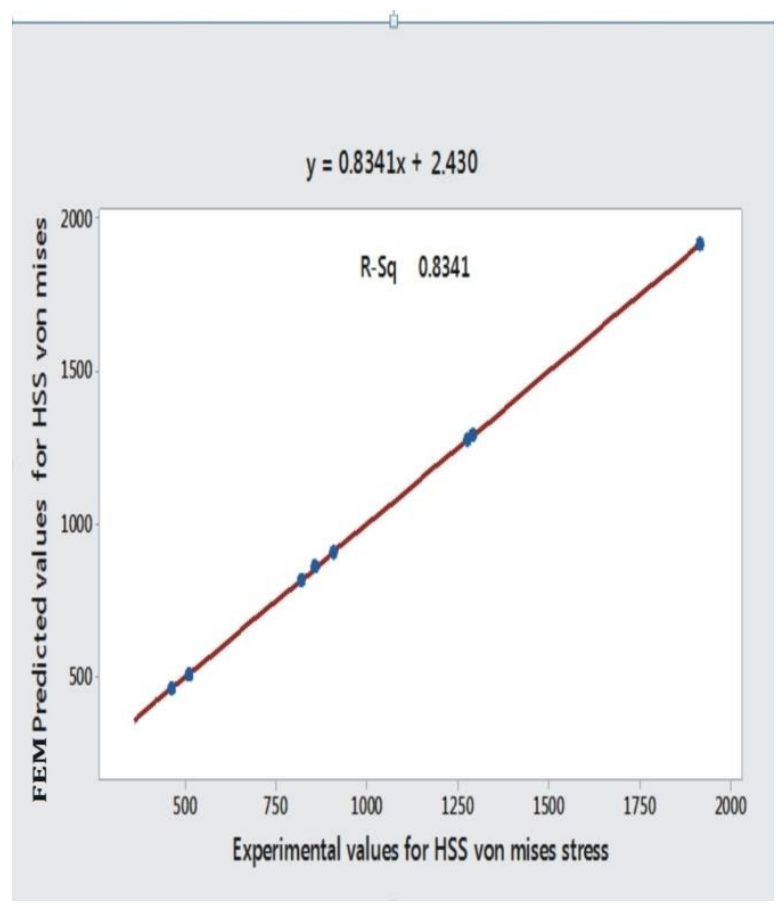

Figure 6 Reliability plots of Experimental and Finite element

From table 5, it can be seen that both experimental and FEM (ANSYS) reading were in close agreements, with a mean absolute percentage error of $0.544 \%$. To assess the accuracy of the predictions as well as the suitability of the finite element model, a reliability plot of the experimental and the predicted values was carried out, as shown in Figure 6. The clustered points along the line in Figure 6 show the closeness between the experimental and the predicted values. This research therefore has clearly shows that ANSYS is a very robust predictive tool, which can be used to model and predict stresses in cutting tools.

\section{CONCLUSION}

The present research study focused on predicting high speed steel cutting tool at various cutting parameters while machining mild steel under dry condition. The experimental design was conducted by the three factors Box-Behnken design. During, the cutting tool tests, the strain gauge was connected to an A.C supply strain meter, which was used to measure the induced strain from which the stress was generated. The FEM software was used to verify the test results. In all, the following conclusions have been drawn;

1. The FEA result shows that the von mises stress are found at the tip of the cutting tool.

2. The experimental test shows that the chip formations were found to be a continuous type at lower spindle speed and feed rate. According to findings [13]. 
3. As depth of cut increases from 0.5 to $1.5 \mathrm{~mm}$ there is a sudden rise in tools' von mises stresses. This is the major reasons of tools' wears and failures, due to increased deformations

From the obtained results, it has been showed that the predictions of the von mises stress of a cutting tool can improve the service life of the cutting tool as well as the integrity of the machined components. It is therefore recommended that the metal cutting industries should adopt FEM Expert means such as the ANSYS, to determine the right process parameter for a specified cutting process, in order to prolong the service life of the cutting tools and avoid exceeding the yield point; the cause of tool wear and failure when machining mild steel with high speed steel cutting tools.

\section{ACKNOWLEDGEMENT}

The entire staff of Prototype Engineering Development Institute (PEDI), Ilesa, Osun state, Nigeria where the 2060 Electronic numerical controlled (ENC) model lathe used for this study, also worthy of mention is the university of Benin faculty of engineering laboratory

\section{REFERENCES}

[1]. Lazoglu, L. and Altintas, Y. (2002) Prediction of tool chip temperature in continuous and interrupted machining. Int. J. Mach. Tools Manufacture. Vol. 42, PP. 1011-1022.

[2]. Lawani, D. I., Mehta, N. K and Jain, P. K (2008) Experimental Investigations of Cutting Parameters Influence on Cutting Forces and Surface Roughness in Finish Hard Turning of 250 Steel. Journal of Materials Processing and Technology, Vol. 206, PP. 167-179.

[3]. Ozel, T. and Zeren, E. (2004) "Determination of Work Material Flow Stress and Friction For FEA Of Machining Using Orthogonal Tests". Journal of Material Processing Technology, PP. 153-154, \& 1019-1025.

[4]. Yen, Y. C., Sohner J., Weule H., Schmidt J. and Altan T. (2003)Estimation of Tool Wear of Carbide Tool in Orthogonal
Cutting using Finite Element Method Simulation, Machining Science and Technology, Vol. 6, PP. 467-486.

[5].Maranhao C. and Davim J. P. (2011). "The Role Of Flow Stress And Friction Coefficient In Fem Analysis Of Machining: A Review". Rev.Adv. Mater. Sci. 30 (2012) 184188

[6]. Outeiro, J. C., Pina, J. C., M'saoubi, R., Pusauec, .F and Jawahir, I.S. (2008) Analysis Of Residual Stresses Induced by Dry Turning of Difficult-To-Machine Materials. CIRP Annals - Manufacturing Technology, Vol. 57, Pp. 77-80.

[7]. Altan, T. and Semiatim (2012) Measurement and Interpretation of Flow Stress Data for the Simulation of MetalForming Processes. Air Force Research Laboratory, Materials and Manufacturing Directorate, Ohio. The Ohio State University Columbus, $\mathrm{Oh}$.

[8]. Grzesik and Wanat (2006) Influence of Tool Wear on Surface Roughness in Hard Turning using different Shaped Ceramic Tools Wear, Vol. 265, PP. 327-335.

[9]. Chou, K. Y., Evans, J. C. and Barash, M. M. (2002) Experimental Investigation on CBN Turning of Hardened AISI 52100 Steel. Journal of Materials Processing Technology, Vol.124, PP. 274-283.

[10]. Benga, G. C and Abrao, A. M. (2013)Turning of Hardened 100 Cr 6 Bearing Steel with Ceramic and PCBN Cutting Tools. Journal of Materials Processing Technology, Vol.143-144, PP. 237-241.

[11]. Collins Eruogun Etin-osa and Joseph Ifeanyi Achebo. (2017). Analysis of Optimum Butt Welded Joint for Mild Steel Components Using FEM (ANSYS). American Journal of Naval Architecture and Marine Engineering DOI: 10.11648/j.aas.20170206.12

[12]. Sharma, A.V.N.I., Raji, Satyanarayana, Gopichand, A. and Subbaiah, K.V (2012) Optimization of cutting parameters on mild steel with HSS and Cemented Carbide tipped tools using ANN. International journal of Research in Engineering and Technology. ISSN2319-1163, Vol. 1, PP.1-4.

[13]. Ozel, Trugrul, And Taylan, Altan. (2000) Determination of Work Piece Flow Stress and Friction at the Chip-Tool Contact for High-Speed Cutting. International Journal of Machine Tools and Manufacture, Vol. 40, PP. 133-152. 